Témoigner Témoigner. Entre histoire et mémoire

Getuigen Revue pluridisciplinaire de la Fondation Auschwitz

$124 \mid 2017$

La musique dans les camps

\title{
Drie Griekse kerken in Centraal-Afrika: Russische Herinneringsplaatsen
}

Trois églises grecques en Afrique centrale : lieux de mémoire russes

\section{Vladimir Ronin}

Traducteur : Anneleen Spiessens

\section{(2) OpenEdition \\ Journals}

\section{Édition électronique}

URL : https://journals.openedition.org/temoigner/5834

DOI : $10.4000 /$ temoigner.5834

ISSN : 2506-6390

Éditeur :

Éditions du Centre d'études et de documentation Mémoire d'Auschwitz, Éditions Kimé

Édition imprimée

Date de publication : 2 avril 2017

Pagination : 154-159

ISBN : 978-2-930953-00-7

ISSN : 2031-4183

\section{Référence électronique}

Vladimir Ronin, «Drie Griekse kerken in Centraal-Afrika: Russische Herinneringsplaatsen», Témoigner. Entre histoire et mémoire [Online], 124 | 2017, Online op 30 novembre 2021, geraadpleegd op 01 décembre 2021. URL: http://journals.openedition.org/temoigner/5834 ; DOl: https://doi.org/10.4000/ temoigner.5834 


\section{Herinneringsplek}

\section{DRIE GRIEKSE KERKEN \\ IN CENTRAAL-AFRIKA: \\ RUSSISCHE HERINNERINGSPLAATSEN}

Tussen 1870 en 1970 trokken meer dan 700 mannen en vrouwen uit het Russische Keizerrijk naar de Belgische bezittingen in Centraal-Afrika. De meeste van die voormalige onderdanen va de tsar begonnen aan hun koloniaal avontu ha de rutie van 1917 en de buroorogin Rus is vet duizur ven the is ve Ingenieurs, artsen, landbour Afiken, hydro nenis, hydrener allen hech ze

Congo en Ryma koloniale tijd maar ook daarna.

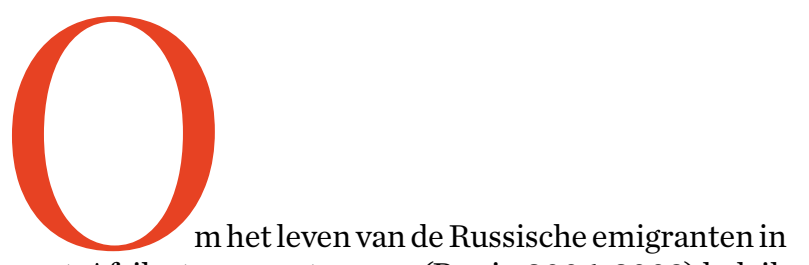
zwart-Afrika te reconstrueren (Ronin 2006; 2009) heb ik zwart-Afilka te reconstrueren (Ronin 2006; 2009) heb ik lijsten die ik in de je ged on rijten die ik in de jarboeken van Belgisch-Congo terugin de ar de person vet vormalige Ministerie van niën. Ik riedplo he ok de Russische persac in de jan re Brussel, Parijs Berijn en Prage Ik hebbovendien dekans sehad om verschillende mémoires, en onuitgegeven brieven te lezen uit de familiegerievien een aantal dussische ex-koloniten

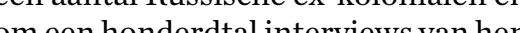
of hun hasten te nemen in Belgie en Frankrijk Tijidens mijn in Belgè en in de Demoratische Repulliek Congo (2011 en 2012) en in Burundien Congo (2012) 2012 ), enin Burundien Cwanda (2015) spormeride pantoch plaatsvond velejaren nahunvertrek uit Afrika, zijn de resultaten weliswaar eerDesheiden, mar niet onbelangrijk. De grote meerderheid van de emigranten was erg gehecht aan het orho-

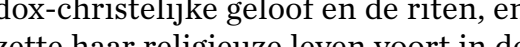
zette haar roligienze leven voort in de tropen voor zover dat mogelijk was. (un clerus hadden de emigranten tijdelijk achtergelaten in Europa. In de grote Grieks-or bedo Russische dispora in de. De kleine Russische diaspora in de industriële rentra van Katanga bijvoorbeeld ging regelmatig, sinds de jaren dertig, naar Lieve-Vrouw Boodschapkerk in ElisaLieve-Vrouw Boodschapkerk in Elisabethstad (nu Lumumbashi). Vooral 
... een eredienst bijwonen in hun eigen liturgische taal, het Kerkslavisch. In oktober 1956 kwam namelijk een oude Russische priester, vader Siméon Starikoff, uit Zuid-Afrika een bezoek brengen aan zijn landgenoten in $\mathrm{Bel}-$ gisch-Congo. Starikoff behoorde tot de Russisch-Orthodoxe Kerk in het Buitenland, een organisatie die Russische emigranten over de hele wereld verenigde. De orthodoxe patriarch van Alexandrië, onder wiens jurisdictie de Grieken van het hele Afrikaanse continent vielen, had de Russische priester kort voor zijn reis de toestemming gegeven om de liturgie te celebreren in de Griekse kerken.

In zijn reisverslag herinnert vader Siméon zich 'de prachtige kerk van Elisatho hoog met een onvergelijkbare akostiek en hoog, met een onvergetijkbare akoestiek en met zijn Griekse (Stak met zijn Griekse collega verzorgde de Russicharvaster de waarvaneengroot deel zichinhet Kerkslavisch sisch. Br was zels sisch koortje dat het publiek bijzonder kon bekoren. Dat koor werd voor de gelegenheid samengesteld door 'een echte kenner van de Russische liturische gezangen', een orthodox-christelijke Belg die even, eens uit Rusland a komstig was. Het ging hier om Antoine het Comité Spéc. Mos du Kat hou Butearts van tienten cientallen Russen uit Elisabethstad Jn Jadot stad zat de kerk afgeladen vol net honderden Grieken die enthousiast en solidair meevierden, zo schrijft een teveden Starikof in zijn van vader Siméon in Jater bezocht de opvolger driet Alexis Tchernai, nog twee maal de Rusdriet Alexis Tchen, nog twee mal de Russen in de grote steden van Congo: in 1959 en In Elisethstad stelden de Griekolo In Elisabethstad stelden de Grieken telkens hun kerk ter beschiking om de liturgie in het Kenslavisch te celebreren. In de mènoires vreugde van zijn lietlezenwe dat de spirituele vreugde van zijn landgenoten niet in woorden eigen kerk, hun eigen riten, hun eigen priester...' (Chernay 1981, 193)

De meest opmerklijke episode in het leven van de Russen in Belgisch Katanga was echter 6 mei 1945 , de dag warop de Russen dat jaa anekdote is verbonden metde Griekse Elisabeths Elisabethstad. De oorlog in Europa liep op zijn inde zelss de Rochtans sterk gekant tegen het Sovjetregime, verde overwiningen van hun volk op de Duitde overwinningen van hun volk op de Duitsers. Ze waren ook opgetogen over een aantal de oorlog hadden voorgeder i zich tijden Stalin $Z$ o werden vorgedaan in het rijk van Rode Lerer in Rode Ler in periode van de tsaren, toonde Stalin zich nogal Kerk, en schakelde de Sovjetproparthodoxe Kerk, en schakelde de Sovjetpropaganda over van hy naar lof voor de 'grootsheid wan de Russisch nale . Op 1 januari nale als unievan devrije ried dat 'onverwoestbare unie vande vije repulieken'bezong, gesmeed Nadepariture Nacte pastiturie van 1945 verlieteengroep Onder hen Grieknd zich Théodorevon Onder hen bevond zich Theodore von der Launitz, een voormaligkapitein van het antibolsjeSint-Petersburg ins Sint-Petersburg onder de tsar, was vermoord de kerk bracht hij de mensen tot. stilstait de kerk bracht hij de mensen tot stilstand en

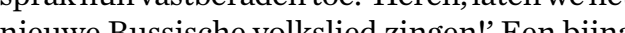
nieuwe Russische volkslied zingen! Een bijna onvorstelbaar tafereel speelde zich toen af op het plein voor de Onze-Lieve-Vrouw Boodzonen van voormalige officilen zonen van voormalige often comnistische renime hadden gestreden in een lange en meedogenloze burgeroorlog, die hat
1941-1942 nog geloofden dat Hitler Rusland ging bevrijden van het rode juk deze mensen brachten publiekelijk, op paszondag en in het centrum van een ande Soveture te vande Sovjetunietenberde. Hetis prins die spont, een van de deelnemers aan die spontane vanifestatie, die me een halve eeuw later de anekdote net ve

Een andere plek in Centraal-Afrika waar menig Russisch emigrant zich niale werk is Bujumbura, de hoofdstad

van Burundi. Iedereen herinnert zich de hevige onrust die ontstond toen op 30 juni 1960 de Congolese onafhankelijkeid werd uitgeroepen. De kolonialen, ok die van Russische afkomst, sloegen massaal op de vlucht voor chaos n geweld. Ze trokken naar Europa, of gingen vanuit oostelijk Congo richting de VN dat in 1960 no trustgebied van de VN dat in 1960 nog onder Belgisch Russischel. Een deel van de hechte Russische gemeenschap die in de jaren vo uit en ron Bukavu woonde, week

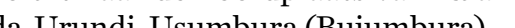

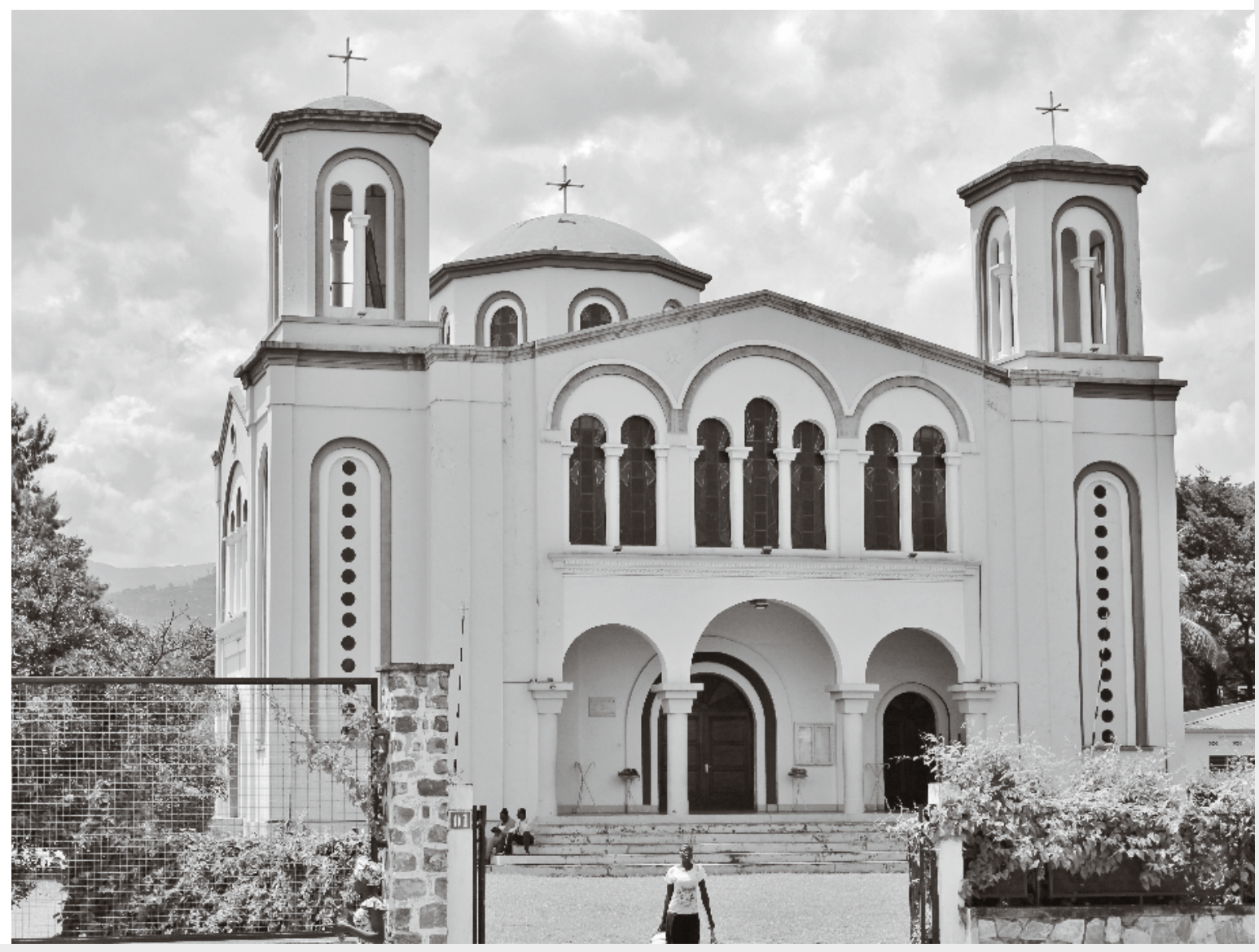


... Tot aan de onafhankelijkheid van Rwanda en Burundi (1962) pendelde landbouwingenieur Vsevolod Kutcharoff tussen Usumbura, waar het in die tijd nog relatief rustig was, en aijn proestation bij Bukavu. In de brieven die hij hoe het orthodoxe pasfeest inso61 werd hij hoe het orthodoxe panseest in 1961 werd gevierd in Usumbura. Op zaterdagavond 8 april,

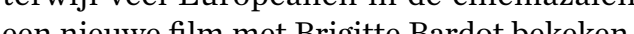
een nieuwe film met Brigitte Bardot bekeken, gingen een tiental Russen naar de vigilie in de was was gebouwd tussen 1955 en 1959 en geldt nu hog als een van de nooiste en m. Kutchorische bouwwerken van Bujumbura. Kutcharoff en den laver de man war we den over de manier waarop de Grieken Pasen vierden dat jaar, zo lezen we in zijn brief: 'Een klucht, dat is het. ledereen hangt hier maar zinloos wat ror snars van

Niet iedereen verliet Congo in 1960. Verschillende Russische ex-kolonialen hadden schillende Russische ex-kolonialen hadden niets te zoeken in Europa: ze hadden er geen familie, geen huis, geen erfenis... Waar moeszelfs 40 an in Afik? In het on zelfs 40 jaar in Afrika? In het onafhankelijke Congo werden daarom een aantal belangrijke cuncties bekle dis vertegenwoordigde graaf Vhadimir Apraxine, een mijningenieur en zoon van de privé-secretaris van de laatse keizen van Rusland, tussen 1964 en 1970 het directorat-generaal van Union Minière (Gécanines vanaf 1966) in Kowezi, en wij grootste industrielecentra vanhet land. Hijwas dusen sleutelfguur in de regio en was op zijn eentje verantwoordelijk vor de'n gehele lokale bevolking, die bestond uit zo'n 5000 Europeanen en 50000 Congolezen. Na de dekolonisatie wist Apraxine zich goed aan te passen aan de nieuwe situatie. Très slave, très grand seigneur' -, 'een echte Slaaf, een echt heerschap' - zo beschreef een
(Marchal 1969,13). De Russische aristocraat straalde een natuurlijk gezag uit, zowel in de mijnen en e fabrieken als in zaken die hij mate van de bevolling vom Kolwe has hem wel erg naw an het hart lag de bouw

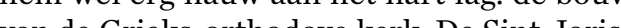
kerk werd pas in 1974 afewerkt, vier jari het vertrek van 'bwa a mer de Griekse gemeen haxp in dit tijd wa hem en zijn echtgencte Mare notlijd was her erg ank de patriarch van Alexaid. de patriarch van Ale a dre. Gravin Marie Apraxine onthulde me later dat ze voor de che cor Afrika. Een halve ee

eeuw, dat is lang. Toen ik in jul 2012 zelf de Sint-Joriskerk in Kolwezi betrad, woonden er bijna geen Grieken meer in de stad. De Congolese orthodoxe parochianen, zelfs de oudsten onder hen, wisten niets over de famikerk Geluklig on tmoette ik bisschop van Katanga, Mr Meletios, dieks bisschop van Katanga, Mgr Meletios, die me onmiddellijk een kleine icoon aanwees die een van de meest vereerde heiligen in Rusland hetberoem Se Klooster van de Heilige Dreve digheid ij Moskou in de verting Driculdigheid bij Moskon in devertiende Driev. Het schitterende icoontje is een unieke en aangrijheid in Criscin postkolon postkoloniale periode. Mgr Meletios vertelde hem in 2005 f 2006 in hem in 2005 of 2006 in Kolwezi opzochten. Ze sie te kopen in Kanga en vroegen de Griekse sie te kopen in Katanga en vroegen de Griekse bisschip toch nog niet an einde. Vladimir Ronin (KUL... Vertalining uit het Frans: Anneleen Spiessens
Vonin (KU Leuven, campus Antwerpen)

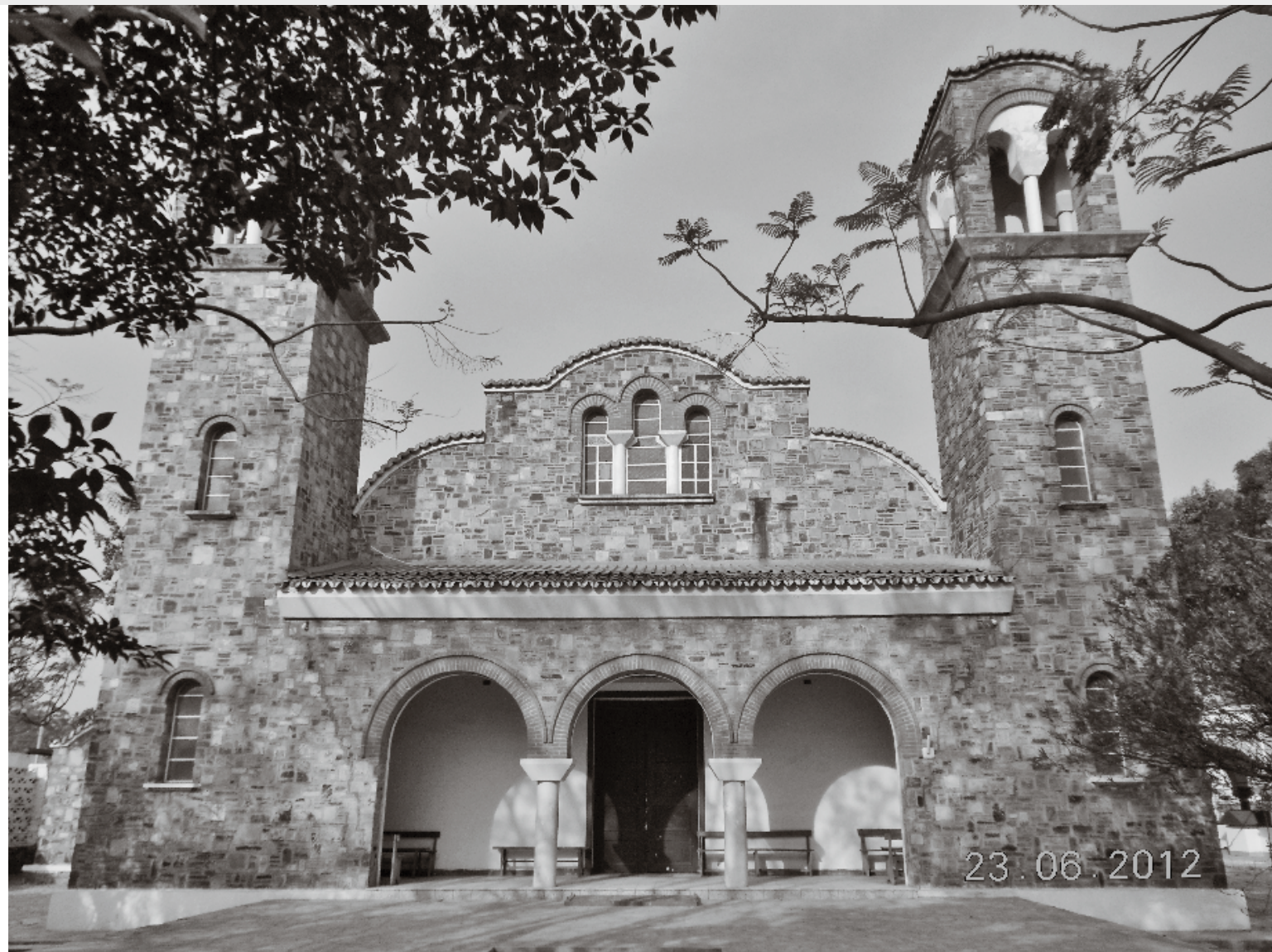

De Grieks-orthodoxe
Sint-Joriskerk in Kolwezi

juli 2012

\section{Bibliografie}

$\triangle$ Alexey Chernay, Russian Odyssey: The Life Path of an Exile, Roodepoort: Cum

Omer Marchal, 'Au nouveau Katanga', Spécial, 2 juli 1969, 10-14. $\widehat{A}$ Vladimir Ronin, 'Les Russes au Congo belge, Contactforum 23 november 2005,
Brussel: Koninklijke Vlaamse Academie voor Wetenschappen en Kunsten, 2006,

$\Delta$ Vladimir Ronin, 'Russkoe Kongo', 1870-1970 [Russisch Congo, 1870-1970], Moscou:
Russkij put, 2009. Russkij put, 2009 $\diamond$ Simeon Starikov, 'Missionerskaja poezdka vglub' Afriki' [Een missiereis naar het hart
van Afrika], Pravoslavnaja Rus' 24, 1956, 15-17. 